\title{
Pulmonary hemodynamic responses to in utero ventilation in very immature fetal sheep
}

\author{
Beth J Allison ${ }^{1 *}$, Kelly J Crossley ${ }^{1}$, Sharon J Flecknoe ${ }^{1}$, Colin J Morley ${ }^{2}$, Graeme R Polglase ${ }^{3}$, Stuart B Hooper ${ }^{4}$
}

\begin{abstract}
Background: The onset of ventilation at birth decreases pulmonary vascular resistance (PVR) resulting in a large increase in pulmonary blood flow (PBF). As the large cross sectional area of the pulmonary vascular bed develops late in gestation, we have investigated whether the ventilation-induced increase in PBF is reduced in immature lungs.

Methods: Surgery was performed in fetal sheep at $105 \mathrm{~d}$ GA $(n=7$; term $\sim 147 \mathrm{~d})$ to insert an endotracheal tube, which was connected to a neonatal ventilation circuit, and a transonic flow probe was placed around the left pulmonary artery. At $110 \mathrm{~d} G$, fetuses $(n=7)$ were ventilated in utero (IUV) for 12 hrs while continuous measurements of PBF were made, fetuses were allowed to develop in utero for a further 7 days following ventilation.
\end{abstract}

Results: PBF changes were highly variable between animals, increasing from $12.2 \pm 6.6 \mathrm{~mL} / \mathrm{min}$ to a maximum of $78.1 \pm 23.1 \mathrm{~mL} / \mathrm{min}$ in four fetuses after 10 minutes of ventilation. In the remaining three fetuses, little change in PBF was measured in response to IUV. The increases in PBF measured in responding fetuses were not sustained throughout the ventilation period and by 2 hrs of IUV had returned to pre-IUV control values.

Discussion and conclusion: Ventilation of very immature fetal sheep in utero increased PBF in 57\% of fetuses but this increase was not sustained for more than 2 hrs, despite continuing ventilation. Immature lungs can increase PBF during ventilation, however, the present studies show these changes are transient and highly variable.

\section{Introduction}

Very preterm infants $(<28$ weeks gestation) are born during the canalicular stage of lung development when the lungs are surfactant-deficient, have a small surface area for gas exchange, a thick air-blood gas barrier and an under-developed pulmonary capillary bed [1]. As a result, very preterm infants commonly suffer respiratory failure after birth and require respiratory support. Although the transition to pulmonary gas exchange is dependent upon major changes in pulmonary hemodynamics, little is known about these changes in infants with very immature lungs and an under-developed pulmonary vascular bed.

During fetal life, pulmonary vascular resistance (PVR) is high and pulmonary blood flow (PBF) is low with most of the blood exiting the right ventricle passing directly into the systemic circulation via the ductus

\footnotetext{
* Correspondence: bethjallison@gmail.com

'Dept of Physiology, Monash University, Melbourne, Australia

Full list of author information is available at the end of the article
}

arteriosus (DA). Indeed, pulmonary blood flows are as low as $\sim 10 \%$ in fetal sheep and $\sim 24 \%$ in human fetuses [2]. The pulmonary arteries develop in parallel with the developing airways [3] and the large cross-sectional surface area of the pulmonary micro-vasculature mainly develops during the saccular and alveolar stages when the distal airways develop [3]. This increase in crosssectional surface area during late gestation, gradually reduces PVR [4] and is a prerequisite for the large and sustained reduction in PVR after birth at term. This is because, at birth, the pulmonary vascular bed must immediately accept the entire output of the right ventricle, allowing closure of the DA, separation of the pulmonary and systemic circulations and a reduction in pulmonary arterial pressure (PAP). Superimposed on this developmental process is an 8-10 fold reduction in PVR associated with birth, caused by the onset of gaseous ventilation [5-7], increased oxygenation [8,9] and the release of vasodilators [10]. 
Previous studies on the birth-related changes in pulmonary hemodynamics have focused on the lungs of either mildly preterm or term neonates, all of which were conducted during the alveolar stage of lung development $[7,11,12]$. During this stage, the alveolar capillary bed is relatively well developed [13] and has a large cross sectional area, giving it the capacity to substantially reduce PVR as ventilation commences. In contrast, in the very immature lung during the canalicular stage, the alveolar vascular bed is still undergoing development and is likely to have a substantially reduced capacity to decrease PVR after birth. However, little is known of the changes in PBF in the very immature lung with the onset of ventilation and so this study has specifically focused on ventilation-induced changes in pulmonary hemodynamics in immature fetal sheep. The results are relevant to understanding pulmonary adaptation at birth in extremely preterm infants.

We have recently developed a technique for ventilating very immature fetal sheep in utero [14]. As the fetus remains on placental support, pulmonary ventilation and other aspects of intensive care management are not required to sustain the lamb's viability, allowing it to be ventilated at a stage (110 d gestation) when lung structure closely resembles that of a human infant at 26-28 weeks of gestation. At $110 \mathrm{~d}$ of gestation, fetal sheep have few immature alveoli [1] with very few differentiated type-II cells [15] and are not viable if ventilated ex utero. Thus, our aim was to examine the effect of in utero ventilation (IUV) on pulmonary hemodynamics during the late canalicular stage of lung development in fetal sheep. We hypothesized that the under-developed pulmonary vascular bed would attenuate the increase in PBF associated with the onset of pulmonary ventilation.

\section{Materials and methods}

\section{Fetal Surgery}

All experimental procedures were approved by the Monash University Animal Ethics Committee. Under general anaesthesia ( $1.5 \%$ halothane in $\left.\mathrm{O}_{2}\right)$, aseptic surgery was performed on seven Border-Leicester X Merino ewes at 105 days gestation (term is $\sim 147$ days) as previously described [14]. A tube (ID $3.2 \mathrm{~mm}$, OD $6.4 \mathrm{~mm}$ ) was inserted into the fetal trachea and connected, via a Y-piece, to two large bore, saline-filled, ventilator circuit tubes (ID $9.5 \mathrm{~mm}$, OD $14.3 \mathrm{~mm}$ ). An additional salinefilled catheter (ID $3.2 \mathrm{~mm}$, OD $6.4 \mathrm{~mm}$ ) was inserted into the fetal upper trachea and connected to a salinefilled ventilation tube to create an exteriorised tracheal loop, allowing the normal flow of liquid into and out of the lung (Figure 1). A 4-mm ultrasonic flow transducer (Transonic Systems; Ithaca, NY) was placed around the left pulmonary artery (31), this probe directly measures blood flow to the left side of the lung (blood flowing

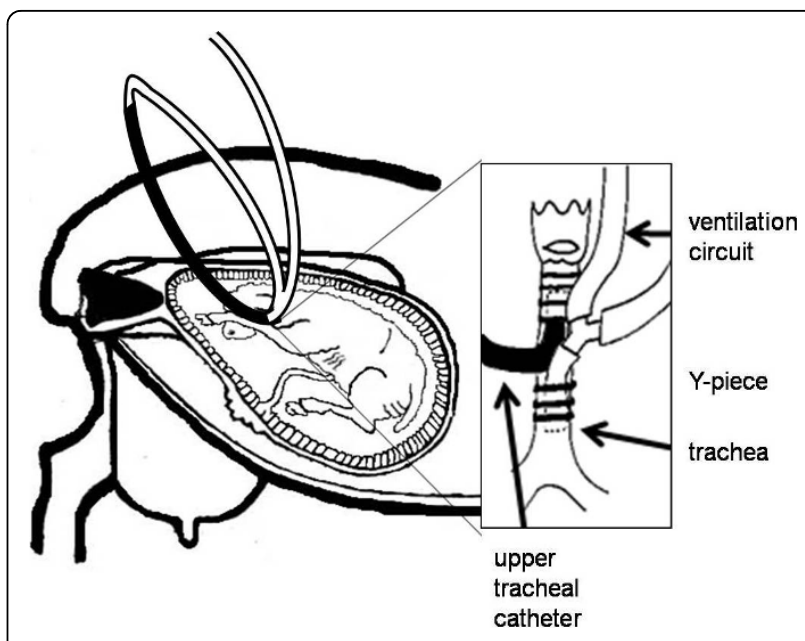

Figure 1 The ventilation circuit (white tubes) was connected to the endotracheal tube via a " $Y$ " piece. An additional catheter was inserted into the upper trachea (black tube) and directed toward the glottis. All catheters were exteriorized via a flank incision. The upper tracheal catheter was connected to the ventilation circuit creating an exteriorized 'tracheal loop' to allow normal flow of lung liquid.

from the right ventricle or shunting left-to-right across the ductus arteriosus). A small securing tie was then inserted into the wall of the vessel and a tapered polyvinyl catheter (BD Insyte Vialon, peripheral venous catheter, length: $48 \mathrm{~mm}, 0.03 \mathrm{~mm}$ ID, $0.041 \mathrm{~mm}$ OD, NJ USA) was inserted into the main pulmonary artery, by direct puncture. It was directed $2 \mathrm{~cm}$ down into the left pulmonary artery before it was secured into place using the securing tie. Polyvinyl catheters were placed in a fetal carotid artery, jugular vein and amniotic sac and exteriorised via the ewe's flank. Ewes and fetuses were allowed 5 days recovery following surgery. Fetal arterial blood $\mathrm{PaO}_{2}, \mathrm{PaCO}_{2}, \mathrm{pH}$ and $\mathrm{SaO}_{2}$ were measured every second day to assess fetal wellbeing.

\section{Experimental Protocol}

Carotid and pulmonary arterial and amniotic sac pressures (DTX, Viggo-Spectramed, California) and blood flow through the left pulmonary artery (LPBF) were recorded digitally at $1 \mathrm{kHz}$ (Powerlab, ADI: Castle Hill, Australia) for 6 hours prior to starting in utero ventilation (IUV). Mean LPBF was calculated electronically from the instantaneous LPBF signal, the LPBF flow measures right ventricular output as well as the left to right shunting through the ductus arteriosus. Prior to IUV, the upper tracheal catheter was disconnected from the ventilator circuit and the liquid within the circuit passively drained by gravity into a sterile bag before connection to a neonatal ventilator (Draeger $8000+)$. Fetuses were ventilated in utero at $110 \mathrm{~d}$ gestation for 12 hrs $(n=7)$ as described previously (briefly 
PIP of $40 \mathrm{cmH}_{2} \mathrm{O}$, PEEP of $4 \mathrm{cmH}_{2} \mathrm{O}$, flow $10 \mathrm{~L} / \mathrm{min}$ and a rate 60 inflations/min; $\mathrm{FiO}_{2} 21 \%$ ); each fetus acted as its own control. However, operated agematched control fetuses were also used for comparison of blood-gases (110 d control fetuses) and fetal weight data (117 d control fetuses). Arterial blood gases were measured hourly. Following IUV, the ventilator circuit and fetal lung were refilled with lung liquid and reconnected to the upper tracheal catheter, to restore normal lung liquid flow [14]. Carotid arterial and amniotic sac pressures as well as PBF were recorded digitally for 6 hours after the cessation of IUV and ewes and fetuses were killed 7 days later (117 d GA) for postmortem analysis.

\section{Pulmonary Blood Flow Waveform Analysis}

Changes in the contour of the PBF waveform were measured by selecting waveforms from 10 consecutive cardiac cycles from each lamb at selected time points during experimentation $[11,16]$ : before IUV (pre-IUV) and then every $5 \mathrm{~min}$ for the first two hours of IUV and at 20 min intervals for the remaining 10 hours of IUV. Waveform parameters and calculations of pulsatility index (PI) have been described previously [11].

\section{Statistical Analysis}

PBF and PAP measurements represent an average value taken over a one minute period of recording with care being taken to avoid periods containing obvious movement artefacts caused by the ewe. Measurements of PBF, systemic arterial pressure (SAP) and PAP are expressed as mean \pm SEM. Heart rate is expressed a percentage increase from the mean heart rate during the pre-IUV recording period. All values were then grouped and means and standard errors determined. Comparisons of PBF, HR, SAP, PAP and individual components of the PBF waveform were analysed using a two-way repeated measures ANOVA using the statistical package Sigma Stat (Version 3.1.1, Jandel Corporation, USA). The level of significance was $\mathrm{p}<0.05$ for all statistical analyses.

\section{Results}

\section{Fetal outcomes}

All fetuses had normal blood gas and acid-base status throughout the experimental period. Although all values were within normal ranges, the $\mathrm{pH}$ values in IUV fetuses were significantly higher than in age-matched controls (Figure 2). No time dependent differences were observed in blood gas and acid base status when compared to age-matched controls. No significant differences were observed between fetal body weights and lung/body weight ratios at post mortem compared to age-matched controls (117 d control; Table 1).

\section{Pulmonary blood flow}

PBF in the left pulmonary artery tended to increase from pre-IUV control values of $6.9 \pm 4.7 \mathrm{~mL} / \mathrm{min}$ to $16.3 \pm 6.1 \mathrm{~mL} / \mathrm{min}$ in response to lung liquid drainage, although this was not statistically significant. The onset of IUV further, and significantly ( $\mathrm{p}<0.001)$, increased PBF from $16.3 \pm 6.1 \mathrm{~mL} / \mathrm{min}$ to a maximum value of $47.2 \pm 19.1 \mathrm{~mL} / \mathrm{min}$ at 10 minutes of IUV (Figure 3A). The PBF then decreased, despite continued mechanical ventilation, such that at 75 minutes after beginning IUV, PBF was not significantly different from pre-IUV values.

The change in PBF in response to IUV varied markedly between fetuses, particularly during the first 90 minutes of IUV, explaining the high variability in PBF displayed in Figure 3A. Based upon the PBF response to IUV, individual fetuses have been subdivided into two groups which differed markedly in their PBF response (Figure 3B). Group (i) called "responders" includes all fetuses with an end-diastolic flow $>0 \mathrm{ml} / \mathrm{min}$ (indicating retrograde flow from the pulmonary arteries had ceased; see Figure 4) and a $>50 \%$ increase in PBF (above control values) (Figure 3B; responders). Group (ii) called "nonresponders", were fetuses who displayed minor or no alterations in PBF (Figure 3B, non-responders), including little change in end-diastolic flow (Figure 4). Of the seven fetuses studied, 4 were responders and 3 nonresponders. GA, body weights and lung weights (Table 1) were not different between the groups.

In comparison to non-responding fetuses, responding fetuses markedly increased PBF in response to IUV, increasing from a pre-IUV value of $12.2 \pm 6.6 \mathrm{~mL} / \mathrm{min}$ to a maximum of $78.1 \pm 23.1 \mathrm{~mL} / \mathrm{min}$ at 10 minutes of IUV after which PBF gradually decreased to return to fetal levels at 2 hours of IUV (Figure 3B). Although all fetuses increased PBF in response to IUV in this group, the extent of the increase varied between fetuses during the early stages of IUV. In contrast, no change in PBF occurred in non-responding fetuses throughout the IUV period (Figure $3 \mathrm{~B}$ ). The changes in PBF were significantly different between responding and non-responding fetuses $(\mathrm{p}<0.001)$ from the beginning until 110 mins of mechanical ventilation.

\section{PBF waveform analysis}

Numerous transient changes in PBF waveform characteristics were noted, although when both groups were combined, only the increases in mean diastolic flow and post-systolic minimum flow at 20 mins of IUV as well as the decrease in pulsatility index at 20 minutes and 2 hours were significant (Table 2). The inability to detect significant changes was largely caused by nonresponding fetuses, as they had little or no variation in their PBF waveform (Figure 4; left hand graphs) in response to IUV. In contrast, fetuses that responded to 


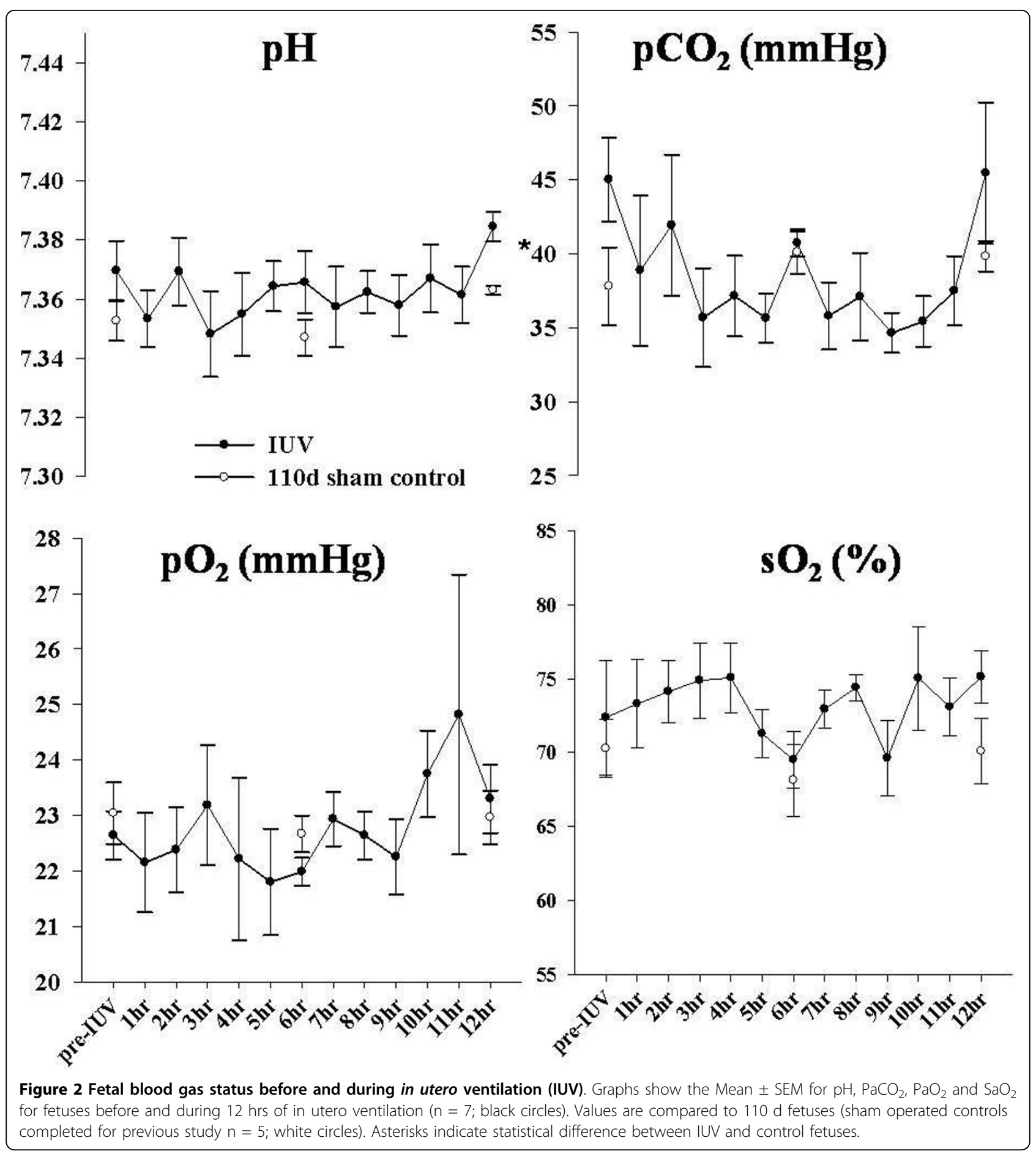

IUV had markedly altered PBF waveforms (Figure 4; right hand graphs) that were similar to what we have shown in more mature fetuses [17].

As we have shown previously during preterm ventilation [17], IUV alter diastolic characteristics of the PBF waveform. Most changes were transient and paralleled changes in mean PBF (Table 3). In responding fetuses, mean diastolic flow, post-systolic minimum flow and end-diastolic flow were all significantly increased (Table 3 ; p < 0.05) from pre-IUV values at 20 minutes of IUV and returned to baseline levels by 2 hrs of ventilation. In 3 out of the 4 responding fetuses, PBF displayed no retrograde flow. PI significantly $(\mathrm{p}<0.05)$, but transiently, decreased in responding fetuses (Table 3). Overall 
Table 1 Fetal body and wet lung weights corrected for body weight (mean \pm SEM)

\begin{tabular}{|c|c|c|c|c|}
\hline & & & \multicolumn{2}{|c|}{ Subgroups } \\
\hline & $117 \mathrm{~d}$ control & $12 \mathrm{hr}$ IUV $+7 \mathrm{~d}$ & Responders & Non-responders \\
\hline GA (days) & $117 \pm 1$ & $117 \pm 1$ & $117 \pm 1$ & $116 \pm 1$ \\
\hline $\mathrm{N}$ & 5 & 7 & 4 & 3 \\
\hline Body weight $(\mathrm{kg})$ & $2.3 \pm 0.3$ & $2.3 \pm 0.3$ & $1.9 \pm 0.1$ & $2.8 \pm 0.4$ \\
\hline Lung weight (g/kg bw) & $33.6 \pm 5.6$ & $64.3 \pm 15.4$ & $76.9 \pm 40.2$ & $51.6 \pm 24.7$ \\
\hline
\end{tabular}

No statistical differences were present between fetuses that either responded or did not respond to IUV. All measurements were made at the time of post mortem.

in all parameters measured, the responding fetuses were significantly different to the non-responding fetuses $(\mathrm{p}<0.001)$.

\section{Heart rate}

Fetal heart rate tended to increase within 30 mins of IUV, although this increase was not significant either when the groups were considered together (Figure 5A) or following separation into responders and non responders (Figure $5 \mathrm{~B}$ ) due to the high level of variability.

\section{Pulmonary and systemic arterial pressure}

Both the PAP and SAP were not significantly altered throughout IUV (Table 4). Following subdivision into groups based on their PBF response to IUV, neither pulmonary nor systemic arterial pressures were significantly altered by IUV (subgroup data not shown).

\section{Discussion}

It is known that ventilation after birth rapidly reduces PVR and increases PBF in mature fetuses at term [7], but how the very immature fetus responds to ventilation is unknown. This study has shown that mechanical ventilation of extremely immature fetal sheep in utero transiently increased PBF in a subgroup of fetuses, although even these fetuses were unable to sustain this increase for longer than 2 hours, despite continuing mechanical ventilation. In the other fetuses, PBF did not increase at any stage during the mechanical ventilation period. The cause of the large variability in pulmonary hemodynamic responses to mechanical ventilation between fetuses remains unknown, although fetal heart rate was also variable. This study is the first to demonstrate the variable PBF response to mechanical ventilation in extremely immature lambs and shows that although the PBF increase is rapid in some lambs, when present it is transient, lasting $<2 \mathrm{hrs}$.

\section{Alterations to Pulmonary Hemodynamics with IUV}

Previous studies have shown that reducing lung liquid volumes in near term fetal sheep, to a volume equivalent to FRC in newborn lambs, decreases PVR and increases PBF 2-4 fold $[18,19]$. Similarly, previous IUV studies conducted in near term fetal sheep have shown that
IUV causes a sustained decrease in PVR and increase in PBF $[7,20,21]$. In this study, lung liquid drainage prior to IUV caused only a small increase PBF, which failed to reach statistical significance, and mechanical ventilation caused a variable increase in PBF in only $~ 57 \%$ of

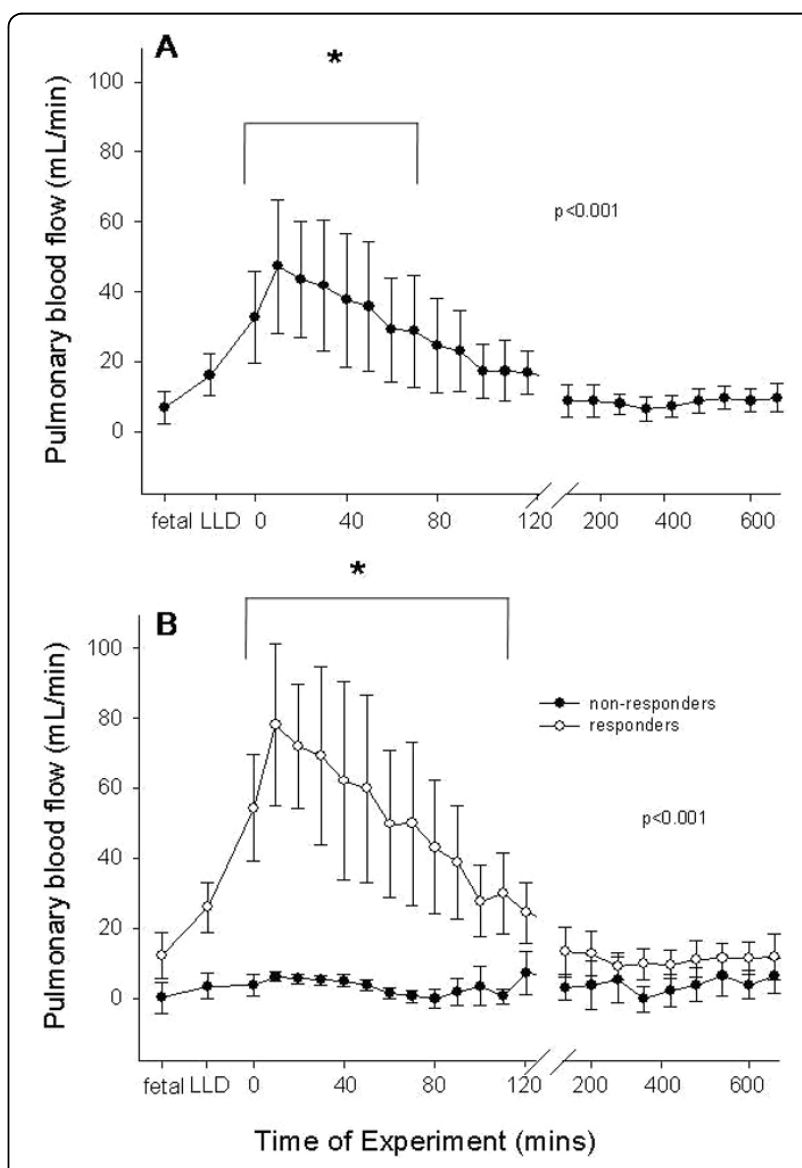

Figure 3 Changes in pulmonary blood flow (PBF) with in utero ventilation (IUV). A) PBF ( $\mathrm{mL} / \mathrm{min}$ ) measured in the left pulmonary artery of IUV exposed fetuses $(n=7)$ pre-IUV, following lung liquid drainage (LLD) and throughout IUV. Asterisks indicate values which are significantly different from pre-IUV values $(p<0.001)$. B) PBF $(\mathrm{mL} / \mathrm{min})$ measured in the left pulmonary artery after sub-division of fetuses into responders (open circles, $n=4$ ) and non-responders (closed circles, $n=3$ ); values were measured pre-IUV, following lung liquid drainage (LLD) and throughout IUV. Asterisks indicate values which are significantly different between responding and nonresponding fetuses $(p<0.001)$. 


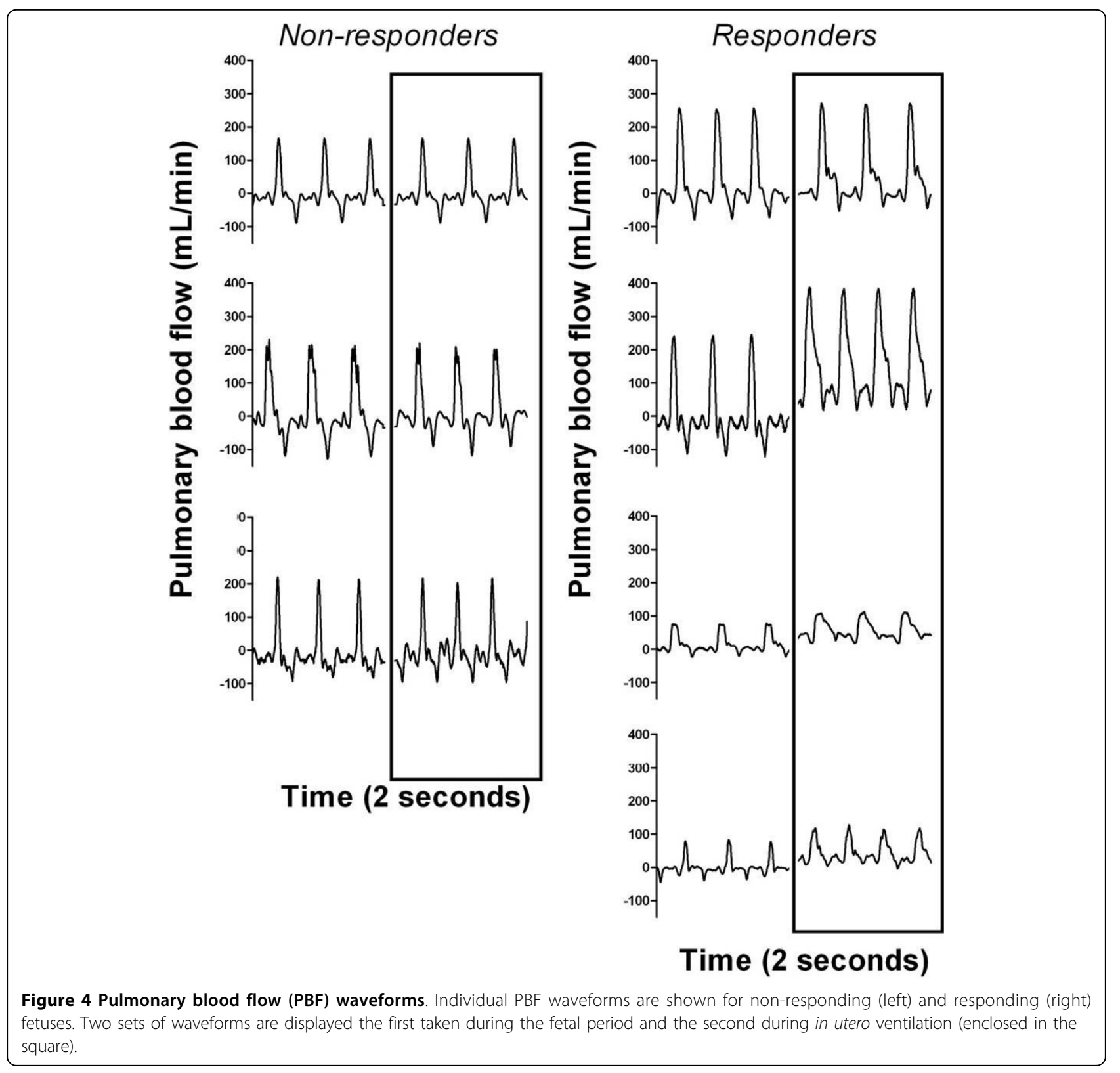

Table 2 Characteristics of the pulmonary blood flow (PBF) waveform in fetuses before, during (at selected time points) and after in utero ventilation (IUV)

\begin{tabular}{|c|c|c|c|c|c|}
\hline \multicolumn{6}{|c|}{ In Utero Ventilation } \\
\hline & Pre-IUV & $20 \mathrm{~min}$ & $2 \mathrm{hr}$ & $11 \mathrm{hr}$ & Post-IUV \\
\hline Peak systolic flow (mL/min) & $189.5 \pm 30.5$ & $228.4 \pm 42.2$ & $179.3 \pm 32.3$ & $177.0 \pm 37.3$ & $189.0 \pm 34.9$ \\
\hline Post-systolic minimum flow (mL/min) & $-78.6 \pm 13.9^{\mathbf{a}}$ & $-32.5 \pm 22.8^{\mathbf{b}}$ & $-68.8 \pm 13.4^{\mathbf{a}}$ & $-80.8 \pm 13.2^{\mathbf{a}}$ & $-75.4 \pm 15.4^{a}$ \\
\hline End-diastolic flow (mL/min) & $-27.1 \pm 4.4$ & $-10.1 \pm 13.9$ & $-26.0 \pm 6.5$ & $-30.7 \pm 7.2$ & $-26.1 \pm 0.3$ \\
\hline Mean diastolic flow (mL/min) & $-17.7 \pm 4.4^{a}$ & $18.4 \pm 2.2^{\mathbf{b}}$ & $-12.6 \pm 3.7^{\mathbf{a}}$ & $-14.1 \pm 3.0^{\mathbf{a}}$ & $-9.6 \pm 5.1^{\mathbf{a}}$ \\
\hline Pulsatility index & $1.4 \pm 0.0^{\mathbf{a}}$ & $1.2 \pm 0.1^{\mathbf{b}}$ & $1.1 \pm 0.1^{\mathbf{b}}$ & $1.47 \pm 0.0^{\mathbf{a}}$ & $1.40 \pm 0.0^{\mathbf{a}}$ \\
\hline Pulse amplitude (mL/min) & $207.8 \pm 31.4$ & $173.1 \pm 37.2$ & $188.4 \pm 28.8$ & $167.1 \pm 34.1$ & $213.1 \pm 42.8$ \\
\hline
\end{tabular}

Values that do not share a common letter are significantly different from each other $(p<0.05)$. 
fetuses. Clearly, the difference between the findings of this study and previous studies is the gestational age and lung maturity at the time of lung liquid drainage and IUV. This suggests that in very preterm infants, with a similar level of lung immaturity, the capacity of the lung to increase PBF in response to mechanical ventilation may be considerably less than previously acknowledged and non-existent in some.

The mechanisms responsible for the increase in PBF at birth in mature, near term, fetuses are thought to be multi-factorial and include effects of ventilation, increased oxygenation and the release of vasodilators [22-24]. NO-induced vasodilation is thought to contribute to $\sim 50 \%$ of the increase in PBF at birth [22] which can be inhibited by blocking NO activity [25]. The mature fetal lung can also vasodilate in response to vasoactive factors, such as prostaglandin $\mathrm{D}_{2}$ [26] and bradykinin [27] both of which can decrease PVR and release vasoactive substances, such as prostaglandins in response to rhythmic distension [28,29]. However, the ability of the very immature pulmonary vascular bed to release NO and other vasodilators and respond to them is relatively unexplored and warrants further investigation.

Changes in transpulmonary pressures associated with lung aeration also contributes to the increase in PBF with ventilation onset $[7,30,31]$. Before birth, the fetal lungs are liquid-filled providing a constant internal distending pressure that maintains the lungs in an expanded state [32,33]. Following lung aeration, the distending influence of lung liquid is lost and the presence of air creates an air-liquid interface [32]. The resulting surface tension, even in the presence of surfactant, increases lung recoil and creates sub-atmospheric intrapleural and peri-alveolar interstitial tissue pressures $[34,35]$. This increases both the capillary/alveolar wall and capillary/interstitial tissue wall transmural pressures leading to an increase in capillary recruitment [36] and expansion of recruited capillaries [31]. On the other hand, increases in intra-luminal pressure caused by positive pressure ventilation, reduces the alveolar/capillary transmural pressure, capillary calibre and increases PVR. This is a well established relationship that has been demonstrated in adults [37], near term fetuses [7], newborns [38] and relatively mature preterm lambs [11].

In adults, the large cross-sectional area of the pulmonary capillary bed allows the pulmonary circulation to accept the entire output of the right ventricle while maintaining pressures at $\sim 1 / 8$ of the systemic circulation. Much of the capillary bed forms (and the crosssectional area of bed increases) during the alveolar stage of lung development, resulting in a gradual reduction in PVR during late gestation [39]. At birth the large decrease in PVR can only occur if the cross-sectional 

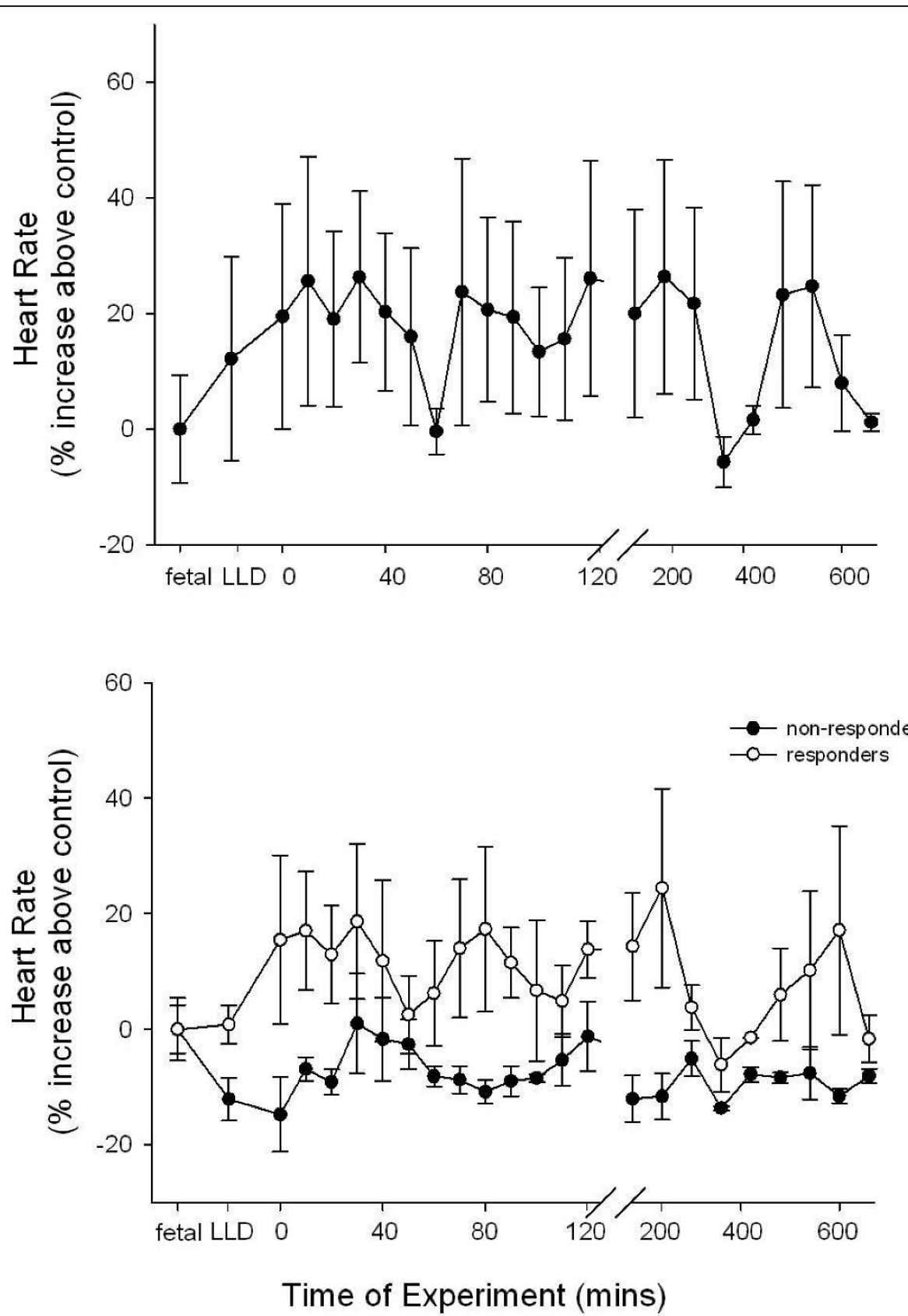

Figure 5 Changes in heart rate with in utero ventilation (IUV). A) Values represent \% increase in heart rate above control values of IUV exposed fetuses ( $n=7$ ) pre-IUV, following lung liquid drainage (LLD) and throughout IUV. B) Values represent \% increase in heart rate above control values in responding (open circles, $n=4$ ) and non-responders (closed circles, $n=3$ ) IUV fetuses; values were measured pre-IUV, following lung liquid drainage (LLD) and throughout IUV.

Table 4 Pulmonary and systemic arterial pressures in fetuses before during (at selected time points) and after in utero ventilation (IUV)

\begin{tabular}{|c|c|c|c|c|c|c|c|c|c|c|}
\hline & \multicolumn{5}{|c|}{ RESPONDERS } & \multicolumn{5}{|c|}{ NON RESPONDERS } \\
\hline & PRE-IUV & $20 \mathrm{~min}$ & $2 \mathrm{hrs}$ & $11 \mathrm{hrs}$ & POST-IUV & PRE-IUV & $20 \mathrm{~min}$ & $2 \mathrm{hrs}$ & $11 \mathrm{hrs}$ & POST-IUV \\
\hline $\begin{array}{l}\text { Pulmonary Arterial } \\
\text { Pressure }(\mathrm{mmHg})\end{array}$ & $37.9 \pm 1.8$ & $36.8 \pm 2.0$ & $38.0 \pm 2.5$ & $36.8 \pm 3.0$ & $40.0 \pm 1.0$ & $38.7 \pm 3.5$ & $31.1 \pm 11.1$ & $39.7 \pm 2.0$ & $40.0 \pm 0.0$ & $32.5 \pm 6.7$ \\
\hline $\begin{array}{l}\text { Systemic Arterial } \\
\text { Pressure }(\mathrm{mmHg})\end{array}$ & $37.4 \pm 3.2$ & $38.0 \pm 4.3$ & $39.5 \pm 4.4$ & $41.9 \pm 3.0$ & $43.0 \pm 2.1$ & $37.7 \pm 3.9$ & $36.2 \pm 5.0$ & $38.4 \pm 3.0$ & $36.5 \pm 3.4$ & $36.7 \pm 2.8$ \\
\hline
\end{tabular}


area of the pulmonary vascular bed is sufficiently large. As very immature lungs will not have undergone this vital development at the time of preterm birth [40] the ability of the immature lung to decrease PVR after birth must be diminished, irrespective of whether they have the capacity to dilate in response to vasodilatory stimuli. Indeed the decrease Pulsatility Index (PI) (Table 2 and 3 ) in fetal sheep following the initiation of mechanical ventilation in the current study indicates that PVR did decrease, although again the increased PI was not maintained for longer than 2 hours. The lack of a pulmonary vascular bed with a sufficiently high cross sectional area may explain why the increase in PBF was not sustained in our study and only occurred in $57 \%$ of fetuses.

The contribution of the low resistance placental circulation must also be considered when interpreting PBF changes in response to IUV, as the placental circulation was functional during our studies. We have recently shown that flow through the ductus arteriosus (DA) reverses with mechanical ventilation at birth, due to a reversal of the pressure gradient across the DA [16]. As a result, the majority of blood flow through the DA immediately after birth, flows from the systemic into the pulmonary circulation (referred to as left-to-right shunting) which contributes $\sim 50 \%$ of PBF that gradually decreases with time [16]. The reversal of the pressure gradient between the systemic and pulmonary circulations $[16,19]$ and the onset of left-to-right shunting through the DA, must be determined by both the decrease in PVR and the increase in downstream resistance in the peripheral vascular bed caused by umbilical cord occlusion. As the umbilical cord was not occluded in this study resistance in the systemic circulation would have remained low limiting the change in pressure gradient across the DA.

Heart rate in the responders, although tending to increase, was not significantly altered throughout the experiment. Given that fetal cardiac output is predominately determined by heart rate rather than stroke volume [41], it is possible that right ventricular output may have contributed to the initial increase in PBF. However, the decrease in PVR (as determined by the pulsatility index) likely plays a greater role in the present study as previously discussed. However, the increase in PBF is likely to have a combination of right and left ventricular output contributions. The responders had positive PBF throughout the cardiac cycle, evident by their respective PBF waveforms (Figure 4), indicating that $100 \%$ of right ventricular output is entering the pulmonary circulation. Left ventricular output may contribute to the increase in PBF as evident by the decrease in the PI (Table 4) which would facilitate left-to-right shunting through the DA. The gradual increase in pulsatility index, likely caused by factors which shall be discussed later, would reduce both left and right ventricular output contributions thus decreasing PBF to normal levels.

\section{The Effect of IUV on Pulmonary Blood Flow Waveform Contour}

In responding fetuses, the contour of the PBF waveform changed in response to IUV to closely resemble the waveform seen in post-natal animals [17], with flow during diastole being particularly affected (Figure 4). Specifically, IUV significantly increased end- and peak-systolic flow as well as end- and mean-diastolic flow, resulting in decreased pulse amplitude in the early stages of IUV. The most significant change was the increase in diastolic flow about 20 mins after mechanical ventilation onset where it remained positive in 3 out of the 4 responding fetuses, indicating blood flowed towards the lung throughout the cardiac cycle at this time. The loss of retrograde flow during diastole is the greatest change to the PBF waveform during fetal to neonatal transition and is a sensitive indicator of a reduced PVR [11]. Thus, the loss of retrograde flow in these very immature fetuses implies that PVR was reduced and that some left-to-right shunting through the DA may have occurred which contributed to the increase in PBF [16]. As diastolic PBF did not increase in nonresponding fetuses, it is unlikely that PVR was significantly reduced or that significant levels of left-to-right shunting occurred in these fetuses in response to IUV.

\section{Other differences between responding and non- responding fetuses}

The two fetal sub-groups had similar arterial pressures and blood gas status before and during IUV, and at autopsy had similar body and organ weights. However, in addition to the PBF changes, responding fetuses increased their heart rate in response to IUV. Although this may have contributed to the increase in PBF, it cannot account for the differences in PBF between subgroups. Indeed, one of the largest changes in PBF in response to IUV was increased diastolic flow, which is largely independent of heart rate and mostly determined by PVR [11]. An increase in fetal heart rate, in the absence of a decrease in PVR, simply results in increased right-to-left flow through the DA. Previous IUV studies conducted in near term fetuses [9,12], also found that maximal increases in PBF occurred in only half of ventilated fetuses [7,42]. Teitel and colleagues (1990) also separated fetuses into major and minor responders (determined by PBF changes) but found no differences between groups other than their response to IUV; they looked at gender, fetal weight, blood gas status, pulmonary vascular tone, ventricular function and alveolar ventilation [7]. We consider the primary difference between responding and non-responding fetuses is the effect of IUV on PVR. 
It is also possible that fetal posture and the influence of the surrounding amniotic fluid may play a role in the differential PBF responses to IUV. Fetal body position cannot be held constant during IUV, either between animals or throughout experimentation in individual animals. Increased fetal flexion is known to increase abdominal pressure and elevate the fetal diaphragm [43] which could limit the tidal volume and distribution of ventilation within the fetal lung. The net result would likely be a marked reduction in the ventilation-induced increase in PBF.

\section{Transient Nature of Hemodynamic Changes}

Despite the period of IUV lasting for 12 hours, the increase in PBF only lasted $\sim 40$ minutes in responding fetuses. Transient PBF changes in response to IUV have not been reported previously although this may be because ventilation only lasted for $30 \mathrm{~min}$ or less in those studies [7-9,42]. Attenuation of increases in PBF have been described in fetuses following occlusion of the DA [44], exposure to high levels of inspired oxygen [45] and to vasodilators [46]. Abman and Accurso (1989) have suggested that the immature vascular bed may have a limited ability to release and maintain the necessary vasodilatory factors needed to sustain an increase in PBF. Alternatively, it is possible that PVR progressively increases, after an initial decrease, due to compression of the capillaries from increased interstitial tissue pressure caused by lung liquid retention in the tissue [35] or to oedema caused by injury [47]. It is also possible that an increase in vasoconstrictive properties within the vascular bed caused by neural, humoral, local or a myogenic responses contributes to the transient nature for the increase in PBF [44]. Shear stress associated with mechanical ventilation is known to elicit myogenic responses [48] which the pulmonary vasculature is particularly sensitive to during the perinatal period [49].

In summary, our studies indicate that despite significant structural immaturity, the very immature lung can increase PBF in response to mechanical ventilation although changes are transient and highly variable. As previous studies, conducted ex utero, have not demonstrated the same variability this suggests either the degree of lung immaturity or the in utero environment is associated with the variability. Understanding the changes in pulmonary hemodynamics at birth in the extremely immature lung is necessary to improve the care and management of extremely preterm infants.

\footnotetext{
Abbreviations

DA: Ductus arteriosus; GA: Gestational age; IUV: In utero ventilation; LPBF: Left pulmonary arterial blood flow; PAP: Pulmonary arterial pressure; PBF: Pulmonary blood flow; PI: Pulsatility index; PVR: Pulmonary vascular resistance; SAP: Systemic arterial pressure
}

\section{Acknowledgements}

We are indebted to Ms Alison Moxham, Ms Valerie Zahra and Mr Alex Satragno for their expert technical assistance.

\section{Author details}

${ }^{1}$ Dept of Physiology, Monash University, Melbourne, Australia. ${ }^{2}$ Neonatal Research, Royal Women's Hospital, Melbourne, Australia. ${ }^{3}$ School of Women's and Infants' Health, The University of Western Australia, Perth, Australia. ${ }^{4}$ Department of Obstetrics and Gynaecology, Monash Institute of Medical Research, Melbourne, Australia.

\section{Authors' contributions}

BA participated in designing the experiments, carried out experiments, analysis of data and drafting of the manuscript. KC assisted with experiments and assisted in drafting of the manuscript. SF assisted with experiments and drafting of the manuscript. CM assisted with the analysis of data and drafting of the manuscript. GP assisted with the analysis of data and drafting of the manuscript. SH participated in designing the experiments, assisted with experiments, analysis of data and drafting of the manuscript. All authors read and approved the final manuscript.

\section{Competing interests}

The authors declare that they have no competing interests.

Received: 8 April 2010 Accepted: 19 August 2010

Published: 19 August 2010

\section{References}

1. Alcorn DG, Adamson TM, Maloney JE, Robinson PM: A morphologic and morphometric analysis of fetal lung development in the sheep. Anat Rec 1981, 201:655-667

2. Rasanen J, Huhta JC, Weiner S, Wood DC, Ludomirski A: Fetal branch pulmonary arterial vascular impedance during the second half of pregnancy. Am J Obstet Gynecol 1996, 174:1441-1449.

3. Hislop A, Reid L: Intra-pulmonary arterial development during fetal life branching pattern and structure. J Anat 1972, 113:35-48.

4. Rudolph AM, Heymann MA: Control of the Foetal circulation. Foetal and neonatal physiology Proceedings of the Sir Joseph Barcroft centenary symposium The Physiological Laboratory Cambridge 25 to 27 of july 1972 London: Cambridge University Press 1973, 89-111.

5. Dawes GS, MILNE ED, Mott JC, Widdicombe JG: The closure of the foramen ovale after birth. J Physiol 1953, 122:38P.

6. Heymann MA: Control of the pulmonary circulation in the fetus and during the transitional period to air breathing. Obstet Gynecol 1999, 84:127-132.

7. Teitel DF, Iwamoto HS, Rudolph AM: Changes in the pulmonary circulation during birth-related events. Pediatr Res 1990, 27:372-378.

8. Banerjee A, Roman C, Heymann MA: Bradykinin receptor blockade does not affect oxygen-mediated pulmonary vasodilation in fetal lambs. Pediatr Res 1994, 36:474-480.

9. Moore P, Velvis H, Fineman JR, Soifer SJ, Heymann MA: EDRF inhibition attenuates the increase in pulmonary blood flow due to oxygen ventilation in fetal lambs. J Appl Physiol 1992, 73:2151-2157.

10. Abman SH, Chatfield BA, Hall SL, McMurtry IF: Role of endotheliumderived relaxing factor during transition of pulmonary circulation at birth. Am J Physiol 1990, 259:H1921-H1927.

11. Polglase GR, Morley CJ, Crossley KJ, Dargaville P, Harding R, Morgan DL, Hooper SB: Positive end-expiratory pressure differentially alters pulmonary hemodynamics and oxygenation in ventilated, very premature lambs. J Appl Physiol 2005, 99:1453-1461.

12. Morin FCl, Egan EA: Pulmonary hemodynamics in fetal lambs during development at normal and increased oxygen tension. J Appl Physiol 1992, 73:213-218.

13. Levin DL, Rudolph AM, Heymann MA, Phibbs RH: Morphological development of the pulmonary vascular bed in fetal lambs. Circulation 1976, 53:144-151.

14. Allison BJ, Crossley KJ, Flecknoe SJ, Davis PG, Morley CJ, Harding R, Hooper SB: Ventilation of the very immature lung in utero induces injury and BPD-like changes in lung structure in fetal sheep. Pediatr Res 2008, 64:387-392. 
15. Flecknoe SJ, Wallace MJ, Cock ML, Harding R, Hooper SB: Changes in alveolar epithelial cell proportions during fetal and postnatal development in sheep. Am J Physiol Lung Cell Mol Physiol 2003, 285: L664-L670.

16. Crossley KJ, Allison BJ, Polglase GR, Morley CJ, Davis PG, Hooper SB: Dynamic changes in the direction of blood flow through the ductus arteriosus at birth. J Physiol-London 2009, 587(Pt 19):4695-4703.

17. Polglase GR, Wallace MJ, Morgan DL, Hooper SB: Increases in lung expansion alter pulmonary hemodynamics in fetal sheep. J Appl Physiol 2006, 101:273-282

18. Walker AM, Ritchie BC, Adamson TM, Maloney JE: Effect of changing lung liquid volume on the pulmonary circulation of fetal lambs. J Appl Physiol 1988, 64:61-67.

19. Hooper SB: Role of luminal volume changes in the increase in pulmonary blood flow at birth in sheep. Exp Physiol 1998, 83:833-842.

20. Rudolph AM, Heymann MA: Hemodynamic changes induced by blockers of prostaglandin synthesis in the fetal lamb in utero. Adv Prostaglandin Thromboxane Res 1978, 4:231-237.

21. Reid DL, Thornburg KL: Pulmonary pressure-flow relationships in the fetal lamb during in utero ventilation. J Appl Physiol 1990, 69:1630-1636.

22. Rairigh RL, Parker TA, Ivy DD, Kinsella JP, Fan ID, Abman SH: Role of inducible nitric oxide synthase in the pulmonary vascular response to birth-related stimuli in the ovine fetus. Circ Res 2001, 88:721-726.

23. Abman SH: Developmental physiology of the pulmonary circulation. In The Lung: Development, Aging and the Environment. Edited by: Harding R, Pinkerton KE, Plopper CG. Oxford: Butterworth Heinemann; 2004:105-117.

24. Leffler CW, Hessler JR, Green RS: Mechanism of stimulation of pulmonary prostacyclin synthesis at birth. Prostaglandins 1984, 28:877-887.

25. Abman SH, Chatfield BA, Hall SL, McMurtry IF: Role of endotheliumderived relaxing factor during transition of pulmonary circulation at birth. Am J Physiol 1990, 259:H1921-H1927.

26. Cassin S: Role of prostaglandins and thromboxanes in the control of the pulmonary circulation in the fetus and newborn. Semin Perinatol 1980, 4:101-107.

27. Campbell AGM, Cockburn F, Dawes GS, Milligan JE: Pulmonary Vasoconstriction in asphyxia during cross-circulation between twin foetal lambs. J Physiol 1967, 192:111-121.

28. Velvis $H$, Moore $P$, Heymann MA: Prostaglandin inhibition prevents the fall in pulmonary vascular resistance as a result of rhythmic distension of the lungs in fetal lambs. Pediatr Res 1991, 30:62-68.

29. Leffler CW, Hessler JR, Green RS: The onset of breathing at birth stimulates pulmonary vascular prostacyclin synthesis. Pediatr Res 1984, 18:938-942.

30. Hooper SB, Kitchen MJ, Wallace MJ, Yagi N, Uesugi K, Morgan MJ, Hall C, Siu KK, Williams IM, Siew M, et al: Imaging lung aeration and lung liquid clearance at birth. FASEB $J$ 2007, 21:3329-3337.

31. Hooper SB, Harding R: Role of aeration in the physiological adaptation of the lung to air-breathing at birth. Current Respiratory Medicine Reviews 2005, 1:185-195.

32. Hooper SB, Harding R: Fetal lung liquid: a major determinant of the growth and functional development of the fetal lung. Clin Exp Pharmacol Physiol 1995, 22:235-247.

33. Harding R, Hooper SB: Regulation of lung expansion and lung growth before birth. J Appl Physiol 1996, 81:209-224.

34. Avery ME, Cook CD: Volume-pressure relationships of lungs and thorax in fetal, newborn, and adult goats. J Appl Physiol 1961, 16:1034-1038.

35. Miserocchi G, Negrini D, Del Fabbro M, Venturoli D: Pulmonary interstitial pressure in intact in situ lung: transition to interstitial edema. J Appl Physiol 1993, 74:1171-1177.

36. Lipsett J, Hunt K, Carati C, Gannon B: Changes in the spatial distribution of pulmonary blood flow during the fetal/neonatal transition: an in vivo study in the rabbit. Pediatr Pulmonol 1989, 6:213-222.

37. Olson $L E$, Wardle RL: Effect of a regional increase in alveolar pressure on pulmonary blood flow. J Appl Physiol 1992, 73:1291-1296.

38. Fuhrman BP, Smith-Wright DL, Kulik TJ, Lock JE: Effects of static and fluctuating airway pressure on intact pulmonary circulation. J Appl Physiol 1986, 60:114-122.

39. Rudolph AM: Fetal and neonatal pulmonary circulation. Annu Rev Physiol 1979, 41:383-395.

40. Reid L, Meyrick B: Microcirculation: definition and organization at tissue level. Ann N Y Acad Sci 1982, 384:3-20.
41. Rudolph AM, Heymann MA: Cardiac output in the fetal lamb: The effects of spontaneous and induced changes of heart rate on right and left ventricular output. Am J Obstet Gynecol 1976, 124:183-192.

42. Iwamoto HS, Teitel DF, Rudolph AM: Effects of lung distension and spontaneous fetal breathing on hemodynamics in sheep. Pediatr Res 1993, 33:639-644.

43. Harding R, Hooper SB, Dickson KA: A mechanism leading to reduced lung expansion and lung hypoplasia in fetal sheep during oligohydramnios. Am J Obstet Gynecol 1990, 163:1904-1913.

44. Abman SH, Accurso FJ: Acute effects of partial compression of ductus arteriosus on fetal pulmonary circulation. Am J Physiol 1989, 257: H626-H634.

45. Accurso FJ, Alpert B, Wilkening RB, Peterson RG, Meschia G: Timedependent response of fetal pulmonary blood flow to an increase in fetal oxygen tension. Respir Physiol 1986, 63:43-52.

46. Accurso FJ, Wilkening RB: Temporal response of the fetal pulmonary circulation to pharmacologic vasodilators. Proc Soc Exp Biol Med 1988, 187:89-98.

47. Schuster DP, Haller J: A quantitative correlation of extravascular lung water accumulation with vascular-permeability and hydrostatic-pressure measurements - apositron emission tomography study. Journal of Critical Care 1990, 5:161-168.

48. Storme L, Rairigh RL, Parker TA, Kinsella JP, Abman SH: In vivo evidence for a myogenic response in the fetal pulmonary circulation. Pediatr Res 1999, 45:425-431.

49. Belik J, Keenley FW, Baldwin F, Rabinovitch M: Pulmonary hypertension and vascular remodeling in fetal sheep. Am J Physiol 1994, 266: h2303-h2309.

doi:10.1186/1465-9921-11-111

Cite this article as: Allison et al:: Pulmonary hemodynamic responses to in utero ventilation in very immature fetal sheep. Respiratory Research 2010 11:111.

\section{Submit your next manuscript to BioMed Central and take full advantage of:}

- Convenient online submission

- Thorough peer review

- No space constraints or color figure charges

- Immediate publication on acceptance

- Inclusion in PubMed, CAS, Scopus and Google Scholar

- Research which is freely available for redistribution

Submit your manuscript at www.biomedcentral.com/submit
Biomed Central 